[4] Helliwell PS et al, Ann Rheum Dis. 2013;72:986-91.

Disclosure of Interest: L. Coates Grant/research support from: Abbvie, Janssen, Consultant for: Abbvie, BMS, Celgene, Pfizer, UCB, MSD, Novartis, Lilly, Janssen, Sun Pharma, D. Gladman Grant/research support from: Amgen, AbbVie, BMS, Celgene, Eli Lilly, Janssen, Novartis, Pfizer and UCB, P. Nash Grant/research support from: Novartis, Abbvie, Roche, Pfizer, BMS, Janssen, and Celgene, Consultant for: Novartis, Abbvie, Roche, Pfizer, BMS, Janssen, and Celgene, Speakers bureau: Novartis, Abbvie, Roche, Pfizer, BMS, Janssen, and Celgene, O. Fitzgerald Grant/research support from: Bristol-Myers Squibb, Roche, Abbott, Consultant for: Bristol-Myers Squibb, Roche, Abbott, A. Kavanaugh Consultant for: Novartis, L. Rasouliyan Consultant for: Novartis through employment at RTI Health Solutions, Employee of: RTI Health Solutions, L. Pricorp Shareholder of: Novartis, Employee of: Novartis, K. Ding Shareholder of: Novartis, Employee of: Novartis, C. Gaillez Shareholder of: Novartis, BMS, Employee of: Novartis DOI: 10.1136/annrheumdis-2017-eular.1458

\section{SAT0463 SECUKINUMAB PROVIDES SUSTAINED REDUCTION IN FATIGUE IN PATIENTS WITH ACTIVE PSORIATIC ARTHRITIS THROUGH 3 YEARS: LONG-TERM DATA FROM THE FUTURE 1 AND FUTURE 2 STUDIES}

L. Gossec ${ }^{1}$, T.K. Kvien ${ }^{2}$, P.G. Conaghan ${ }^{3}$, M. Østergaard ${ }^{4}$, D. Gladman ${ }^{5}$ P. Mease ${ }^{6}$, L. Rasouliyan 7 , L. Pricop ${ }^{8}$, C. Gaillez ${ }^{9}$, S. Jugl ${ }^{9} .{ }^{1}$ UPMC University Paris 06, Paris, France; ${ }^{2}$ Diakonhjemmet Hospital, Oslo, Norway; ${ }^{3}$ University of Leeds, Leeds, United Kingdom; ${ }^{4}$ Copenhagen Center for Arthritis Research (COPECARE), Glostrup, Denmark; ${ }^{5}$ University of Toronto, Toronto, Canada; ${ }^{6}$ Swedish Medical Center, Seattle, WA, United States: ${ }^{7} R T I$ Health Solutions, Barcelona, Spain; ${ }^{8}$ Novartis Pharmaceuticals Corporation, East Hanover, NJ, United States; ${ }^{9}$ Novartis Pharma AG, Basel, Switzerland

Background: Fatigue, a common symptom in patients (pts) with PsA, can negatively impact HRQoL and social functioning. Secukinumab (SEC), a fully human anti-IL-17A mAb, rapidly improved signs and symptoms, physical functioning, HRQoL, and fatigue in pts with PsA. ${ }^{1,2}$

Objectives: To assess the long-term effects of SEC on fatigue in TNF inhibitor (TNF)-naïve PsA pts and those with an inadequate response or intolerance to TNF inhibitor therapy (TNF-IR).

Methods: 606 and 397 pts were randomized to SEC or placebo (PBO) in FUTURE 1 (10 mg/kg IV followed by 150 or $75 \mathrm{mg} \mathrm{SC}$ ) and FUTURE 2 (300, 150 , or $75 \mathrm{mg} \mathrm{SC}$ ), respectively. At Wk $16, \mathrm{PBO}$ pts with $\leq 20 \%$ reduction in tender/swollen joint count (non-responders) were re-randomized to SEC 150 or $75 \mathrm{mg} \mathrm{SC}$ (FUTURE 1) and SEC 300 or $150 \mathrm{mg} \mathrm{SC} \mathrm{(FUTURE} \mathrm{2);} \mathrm{responders}$ were re-randomized at Wk 24. Pts in FUTURE 1 could enter a LTE study at Wk 104 (NCT01892436). Across both studies, approximately 68\% of pts were TNF-naïve and $32 \%$ were TNF-IR. Fatigue was assessed at baseline (BL) and Wks 4, 8, 12, 16, 24, 52, 104, and 156 (FUTURE 1 only) using FACIT-F (higher scores $=$ less fatigue). Fatigue response was defined by an increase in FACIT-F score of $\geq 4$ from $B L$ (corresponding to the $M C I D$ ). Correlations between $B L$ characteristics and improvements in fatigue were investigated using a logistical regression model. Only data with approved doses of SEC (300/150 mg) are shown.

Results: FACIT-F was 27.8-28.9 and 26.6-29.2 at BL across groups in FUTURE 1 and 2, respectively. Improvements in fatigue seen with all doses of SEC vs. PBO from Wks 4-24 were sustained through 156 wks in FUTURE 1 and 104 wks in FUTURE 2 in both the overall population and subgroups stratified by prior exposure to TNF (Table). The numerically higher responses with SEC 150 vs. $300 \mathrm{mg}$ in this observed analysis were as a result of a higher rate of discontinuation due to lack of efficacy with the lower dose, which inflated the response rate. In the overall population, the LS mean change ( \pm SEM) from $B L$ in FACIT-F was significantly greater with SEC vs. PBO at Wk 16 in both FUTURE 1 ( $7.25 \pm 0.72$ vs. $4.07 \pm 0.76 ; P=0.002)$ and FUTURE 2 (300 mg: $5.89 \pm 0.92$ vs. $1.86 \pm 0.93, P=0.002 ; 150 \mathrm{mg}: 7.40 \pm 0.90$ vs. $1.86 \pm 0.93, P<0.0001)$; improvements were sustained throughout the entire follow up in both studies (FUTURE 1 Wk 156: 6.14 0.77; FUTURE 2 Wk 104: $300 \mathrm{mg} 7.29 \pm 1.04,150 \mathrm{mg} 7.02 \pm 1.06$ ). Improvements were generally somewhat larger in TNF-naïve pts than in TNF-IR pts. Correlation analyses did not identify any BL factors that consistently predicted change in fatigue score across Wks 16, 52, and 104.

Conclusions: SEC-treated PSA pts achieved rapid, sustained, and clinically meaningful improvements in fatigue for up to $156 \mathrm{wks}$, with higher responses in TNF-naïve pts.

References:

[1] McInnes et al. Lancet 2015;386:1137-46.

[2] Mease et al. N Engl J Med 2015;373:1329-39.

Disclosure of Interest: L. Gossec Grant/research support from: BMS, Lippy, Pfizer; Consultant for: Abbvie, BMS, Celgene, Janssen, MSD, Novartis, Pfizer, Roche and UCB, T. Kvien Consultant for: AbbVie, Biogen, BMS, Boehringer Ingelheim, Celltrion, Eli Lilly, Epirus, Janssen, Merck-Serono, MSD, Mundipharma, Novartis, Oktal, Orion Pharma, Hospira/Pfizer, Roche, Sandoz and UCB, Speakers bureau: AbbVie, Biogen, BMS, Boehringer Ingelheim, Celltrion, Eli Lilly, Epirus, Janssen, Merck-Serono, MSD, Mundipharma, Novartis, Oktal, Orion Pharma, Hospira/Pfizer, Roche, Sandoz and UCB, P. Conaghan Consultant for: Abbvie, BMS, Lilly, Novartis, Pfizer, Roche, Speakers bureau: Abbvie, BMS, Lilly, Novartis, Pfizer, Roche, M. Østergaard Consultant for: Abbvie, BMS, Boehringer-Ingelheim,
Table. FACIT-Fatigue responders in FUTURE 1/FUTURE 2 until Week 156/104"

\begin{tabular}{|c|c|c|c|}
\hline \multirow{2}{*}{$\begin{array}{l}\text { Proportion of Patients with FACIT. } \\
\text { Fatigue Response }{ }^{6}, \%(\mathrm{n} / \mathrm{m})\end{array}$} & \multirow{2}{*}{$\begin{array}{l}\text { FUTURE } 1^{\circ} \\
\text { SEC IV-150 } \mathrm{mg}\end{array}$} & \multicolumn{2}{|c|}{ FUTURE 2} \\
\hline & & SEC $300 \mathrm{mg}$ & SEC $150 \mathrm{mg}$ \\
\hline Overall Population & $N=161$ & $N=100$ & $N=100$ \\
\hline Week 16 & $60.4(96 / 159)$ & $50.5(48 / 95)$ & $70.0(70 / 100)$ \\
\hline Week 52 & $66.9(107 / 160)$ & $60.2(56 / 93)$ & $68.5(61 / 89)$ \\
\hline Week 104 & $63.4(90 / 142)$ & $62.4(53 / 25)$ & $70.1(54 / 77)$ \\
\hline Week 156 & $57.4(89 / 155)$ & - & - \\
\hline TNF-naive & $N=120$ & $\mathrm{~N}=67$ & $\mathrm{~N}=63$ \\
\hline Week 16 & $61.3(73 / 119)$ & $52.4(33 / 63)$ & $71.4(45 / 63)$ \\
\hline Wook 52 & $69.2(83 / 120)$ & $60.7(37 / 61)$ & $72.9(43 / 59)$ \\
\hline Week 104 & $63.9(69 / 108)$ & $60.7(34 / 56)$ & $71.7(38 / 53)$ \\
\hline Week 156 & $58.3(67 / 115)$ & - & - \\
\hline TNF-AR & $\mathrm{N}=41$ & $\mathrm{~N}=33$ & $N=37$ \\
\hline Week 16 & $57.5(23 / 40)$ & $46.9(15 / 32)$ & $67.6(25 / 37)$ \\
\hline Woek 52 & $60.0(24 / 40)$ & $59.4(19 / 32)$ & $60.0(18 / 30)$ \\
\hline Woek 104 & $61.8(21 / 34)$ & $65.5(19 / 29)$ & $66.7(16 / 24)$ \\
\hline Week 156 & $55.0(22 / 40)$ & - & - \\
\hline
\end{tabular}

"Observed data are shown; ${ }^{b}$ Defined as improvement 24.0 points: "Data shown are from patients who entered the FUTURE 1 long-term extension study at Week 104 $\mathrm{m}$, number of patients with sufficient data for evaluation; $\mathrm{N}$, number of patients randomized to SEC $150 \mathrm{mg}$ or SEC $300 \mathrm{mg}$ (FUTURE 2 only); $n$, number of responders.

Celgene, Eli-Lilly, Janssen, Merck, Novartis, Orion, Pfizer, Regeneron, Roche, UCB, Speakers bureau: Abbvie, BMS, Boehringer-Ingelheim, Celgene, Eli-Lilly, Janssen, Merck, Novartis, Orion, Pfizer, Regeneron, Roche, UCB, D. Gladman Grant/research support from: Abbvie, Amgen, BMS, Celgene, Eli Lilly, Janssen, Novartis, Pfizer, UCB, Consultant for: Abbvie, Amgen, BMS, Celgene, Eli Lilly, Janssen, Novartis, Pfizer, UCB, P. Mease Grant/research support from: Abbvie, Amgen, BMS, Boehringer-Ingelheim, Celgene, Eli-Lilly, Janssen, Merch, Novartis, Pfizer, SUN, UCB, Consultant for: Abbvie, Amgen, BMS, Boehringer-Ingelheim, Celgene, Eli-Lilly, Janssen, Merch, Novartis, Pfizer, SUN, UCB, Speakers bureau: Abbvie, Amgen, BMS, Boehringer-Ingelheim, Celgene, Eli-Lilly, Janssen, Merch, Novartis, Pfizer, SUN, UCB, L. Rasouliyan Consultant for: Novartis, L. Pricop Shareholder of: Novartis, Employee of: Novartis, C. Gaillez Shareholder of: Novartis and BMS, Employee of: Novartis, S. Jugl Shareholder of: Novartis, Employee of: Novartis

DOI: 10.1136/annrheumdis-2017-eular.1719

\section{SAT0464 THE IDEAL TARGET FOR PSORIATIC ARTHRITIS? COMPARISON OF REMISSION AND INACTIVE DISEASE STATES IN A REAL LIFE COHORT}

L.J.J. Van Mens ${ }^{1}$, A.W.R. van Kuijk ${ }^{2}$, D.L. Baeten ${ }^{1,3}$, L.C. Coates ${ }^{4} .{ }^{1}$ AMC; ${ }^{2}$ Reade, Amsterdam Immunology and Rheumatology Center, Amsterdam, Netherlands; ${ }^{3}$ UCB, Brussels, Belgium; ${ }^{4}$ LIRMM, University of Leeds, Leeds, United Kingdom

Background: Recommendations on psoriatic arthritis (PsA) state that the target of treatment should be remission or inactive disease. Multiple potential targets have been developed and proposed, each with a different composition of clinical measurements.

Objectives: Our aim is to use an existing real life dataset of a large group of patients in a low disease activity state, to compare different targets and provide further evidence to choose a target.

Methods: This analysis uses data from a cross-sectional real life cohort of 250 PsA patients (EULAR16-2124). All patients were considered in an acceptable disease state according to the treating rheumatologist, defined by the fact that the rheumatologist did not consider to modify the current treatment. Remission/inactive disease targets were the DAPSA [TJC; SJC; patient global visual analogue scale (Pt VAS); pain VAS; CRP] and clinical (c)DAPSA [DAPSA minus CRP] remission $(\leq 4)$, very low disease activity (VLDA) $[7 / 7$ of $T J C \leq 1$; $\mathrm{SJC} \leq 1 ; \mathrm{PASI} \leq 1 ; \mathrm{Pt}$ pain $\leq 15 \mathrm{~mm} ; \mathrm{Pt}$ VAS $\leq 20 \mathrm{~mm} ; \mathrm{HAQ} \leq 0.5$; tender entheseal points $\leq 1$, and PASDAS $\leq 1.9$ or near remission (NR).

Results: 113 pts were in CDAPSA remission, 107 in DAPSA remission, 56 met VLDA and 37 in PASDAS NR. There was a very high percentage exact agreement between DAPSA and CDAPSA (96\%) reflecting the similarity of the two definitions. DAPSA/CDAPSA and VLDA show a high correlation (pearson of 0,611 and 0,590 resp) but VLDA is more stringent in comparison with both DAPSA scores. The correlation between NR and DAPSA/cDAPSA/VLDA was lower, (pearson 0,400, 0,403 and 0,412 resp). Again PASDAS NR was generally more stringent than DAPSA/cDAPSA remission but greater dissimilarities are seen between PASDAS NR and VLDA where 14 patients are in VLDA but not PASDAS NR and 29 are in PASDAS NR but not VLDA.

Although presence of active joint disease was similar across the different measures, VLDA presents as a more stringent cutoff with less residual disease in PASI, TJC and less impact on DLQI and HAQ. All targets had similar \% of patients 
with a raised CRP. The DAPSA measures which do not include an enthesitis measure show more patients with an active enthesitis.

There was a limited consequence on QoL measures when residual disease activity was allowed in certain domains in these remission states. In those patients with active enthesitis or skin disease, no differences were found on PROs on quality of life and functionality. The presence of active skin disease with a PASI>2 (present in 20/110 pts achieving DAPSA) was reflected by an impact on DLQI $(2,85(S D 2,9)$ v.s. $1(2,3) p=0.003)$. This effect was not seen when the cutoff of for $\mathrm{PASI}>1$ was used.

\begin{tabular}{|c|c|c|c|c|c|}
\hline & cDAPSA $(n=113)$ & DAPSA $(n=107)$ & VLDA $(n=56)$ & PASDASNR $(\mathrm{n}=37$ \\
\hline \multicolumn{2}{|c|}{ PASDAS mean (SD) } & $2,16(0,52)$ & $2,13(0,49)$ & $1,97(0,42)$ & $1,6(0,20)$ \\
\hline \multirow{3}{*}{ SJC } & 0 & $101(89 \%)$ & $96(90 \%)$ & $53(95 \%)$ & $33(89 \%)$ \\
\hline & 1 & 10 & 10 & 3 & 1 \\
\hline & 2 & & & 0 & \\
\hline \multirow[t]{4}{*}{ TJC } & 0 & $93(82 \%)$ & $89(83 \%)$ & $51(91 \%)$ & $28(75 \%)$ \\
\hline & 1 & 11 & 11 & 5 & 2 \\
\hline & 2 & 7 & 5 & 0 & 4 \\
\hline & $3+$ & 2 & 2 & 0 & 3 \\
\hline \multirow[t]{3}{*}{ LEI } & 0 & $108(96 \%)$ & $102(96 \%)$ & $56(100 \%)$ & $37(100 \%)$ \\
\hline & 1 & 1 & 1 & 0 & 0 \\
\hline & $2+$ & 4 & 4 & 0 & 0 \\
\hline \multirow{2}{*}{ PASI score } & $0-1$ & $79(70 \%)$ & $74(69 \%)$ & $56(100 \%)$ & $32(86 \%)$ \\
\hline & $>1$ & 34 & 33 & 0 & 5 \\
\hline \multicolumn{2}{|c|}{$\mathrm{CRP}>5 \mathrm{mg} / \mathrm{dl}$} & $11(10 \%)$ & $8(7,5 \%)$ & $5(9 \%)$ & $1(3 \%)$ \\
\hline
\end{tabular}

Conclusions: This comparison of the different remission targets shows that VLDA presented as the most stringent target. Inclusion of laboratory markers seems not to be a necessity although the exclusion of a skin domain might result in a negligence of skin disease in some patients despite an impact on their QoL.

Disclosure of Interest: L. Van Mens: None declared, A. van Kuijk Grant/research support from: UCB, Pfizer, MSD, Janssen, Consultant for: Novartis, Celgene, D. Baeten Grant/research support from: Pfizer, MSD, AbbVie, UCB, Novartis, Janssen, Boehringer Ingelheim. This cohort was funded by an unrestricted grant from Pfizer to DB, Consultant for: Pfizer, MSD, AbbVie, UCB, Novartis, Janssen, Boehringer Ingelheim, Eli Lilly, Roche, BMS, Glenmark, Employee of: UCB, L. Coates: None declared

DOI: 10.1136/annrheumdis-2017-eular.2926

\section{SAT0465 AN INTEGRATED SAFETY DATA ANALYSIS ACROSS ALL PHASE II AND PHASE III CLINICAL PROGRAMS FOR USTEKINUMAB IN PSORIATIC ARTHRITIS, CROHN'S DISEASE, AND PSORIASIS}

L.S. Gensler ${ }^{1}$, E. Hsia ${ }^{2}$, C. Gasink ${ }^{2}$, B. Randazzo ${ }^{3}$, D. Parenti ${ }^{4}$, S. Fakharzadeh ${ }^{4}$, L.-L. Gao ${ }^{3}$ S.D. Chakravarty ${ }^{5}{ }^{1}$ University of California, San Francisco, San Francisco; ${ }^{2}$ Janssen Research \& Development, LLC/University of Pennsylvania, Spring House/Philadelphia; ${ }^{3}$ Janssen Research \& Development, LLC, Spring House; ${ }^{4}$ Janssen Scientific Affairs, LLC, Horsham; ${ }^{5}$ Janssen Scientific Affairs, LLC/Drexel University College of Medicine, Horsham/Philadelphia, United States

Objectives: Therapeutic decisions are based on efficacy, but clinicians need to consider medication safety in this process. Here, we report ustekinumab (UST) integrated safety data in patients (pts) with psoriatic arthritis (PsA), Crohn's disease (CD), and psoriasis (PsO). We also compare a subset of PsA pts with \& without baseline methotrexate (MTX).

Methods: Integrated safety data from $3 \mathrm{PsA}, 5 \mathrm{CD}$, \& 4 PsO trials were analyzed. PsA studies included the Ph2 trial [CNTO743T10] \& the $2 \mathrm{Ph} 3$ trials (PSUMMIT 1 \& 2) with 222,615 \& 312 pts exposed to UST, respectively. The percentage of pts in the Ph2 study that received MTX was $20.5 \%$. No concomitant DMARDs with the exception of MTX (approximately $50 \%$ of pts in each study) were permitted in the $2 \mathrm{Ph} 3$ studies. In the $5 \mathrm{CD}$ trials (Ph2/3Ph3) 1749 pts were exposed to UST. In the $3 \mathrm{Ph} 3 \mathrm{CD}$ trials, pts received one dose of UST $130 \mathrm{mg}$ or $\sim 6 \mathrm{mg} / \mathrm{kg}$ IV at induction (UNITI-1 \& UNITI-2), then 8 weeks later, entered the maintenance phase (IM UNITI) and received UST 90mg SC q8w or q12w for 44 weeks. The percentage of pts on background MTX in UNITI- 1 was $9.2 \%$ \& in UNITI-2, $4.8 \%$. In the $\mathrm{PsO}$ studies (1Ph2/3Ph3), a total of $3117 \mathrm{pts}$ received UST $45 \mathrm{mg}$ or $90 \mathrm{mg}$ SC; no concomitant DMARD therapy (including MTX) was permitted. The PsO studies were completed through 5-years of follow-up. All pts who received at least 1 dose of UST are included in this analysis. Safety events are reported in events per 100 -pt years. $95 \% \mathrm{Cl}$ for events per $100 \mathrm{PY}$ were estimated.

Results: Through 1 year of follow-up, a total of 1018 PsA pts were treated with UST, of which 465 were co-treated with MTX. Of the 1749 CD pts treated with UST, 139 received MTX. Discontinuation rates of UST due to adverse events (AEs) were comparable across disease states irrespective of MTX use (Table). $\mathrm{AE}$ rates $(95 \% \mathrm{Cls}$ for events/100 PY) were noted to be comparable in the UST vs PBO groups for all diseases pooled irrespective of MTX use-UST (420.39, $432.45)$ vs PBO $(534.80,570.44)$. Serious adverse event rates (SAEs) were also comparable in the UST vs PBO groups for all diseases pooled-UST $(14.25,16.56)$ vs PBO $(24.05,32.18)$. Infections and Serious infections (SIs) had numerically lower event rates in UST vs. PBO groups for all diseases pooled-UST (122.16, $128.72)$ vs PBO $(120.94,138.27)$ and UST $(2.10,3.05)$ vs PBO $(2.76,6.00)$, respectively (Table). Major adverse cardiovascular events (MACE) did not appear

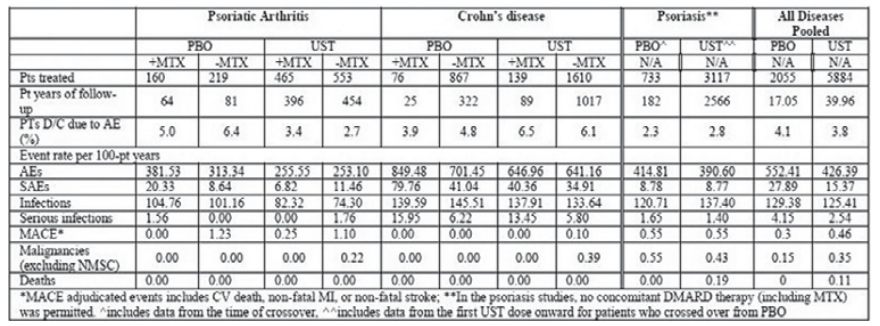

to significantly differ in both PBO \& UST pts in PsA, PsO and CD. Event rates of malignancy (excluding non-melanoma skin cancer) were comparable across all disease states. No deaths in PSA or CD were reported.

Conclusions: UST demonstrates a favorable safety profile in an integrated safety data analysis across the PsA, CD, \& PsO phase $2 \& 3$ clinical trials. The use of UST in PSA appears to be safe \& well-tolerated, with fewer event rates of SAEs \& SIs noted vs PBO. Despite higher overall rates of SAEs \& Sls observed in CD pts, the data do not suggest an influence of UST on either.

Disclosure of Interest: L. Gensler Grant/research support from: Janssen Scientific Affairs, LLC, E. Hsia Employee of: Janssen Research \& Development, LLC C. Gasink Employee of: Janssen Research \& Development, LLC, B. Randazzo Employee of: Janssen Research \& Development, LLC, D. Parenti Employee of: Janssen Scientific Affairs, LLC, S. Fakharzadeh Employee of: Janssen Scientific Affairs, LLC, L.-L. Gao Employee of: Janssen Research \& Development, LLC, S. Chakravarty Employee of: Janssen Scientific Affairs, LLC

DOI: 10.1136/annrheumdis-2017-eular.1116

\section{SAT0466 PREGNANCY IN WOMEN WITH PSORIATIC ARTHRITIS: PREGNANCY OUTCOMES AND CHANGES IN DISEASE ACTIVITY}

M.E.B. Clowse, G. McDaniel, A.M. Eudy. Rheumatology, Duke University Medical Center, Durham, United States

Background: Very little has been published about psoriatic arthritis (PsA) in pregnancy, and it remains unknown whether pregnancy outcomes are impacted by this disease or whether disease activity is changed by pregnancy or delivery. Objectives: To discover the rate of pregnancy complications for women with psoriatic arthritis, and to determine whether psoriasis and the associated arthritis change during and following pregnancy.

Methods: A retrospective survey was completed by 40 women aged 20-50 years with psoriatic arthritis managed at a university center. Each survey collected information about infertility, pregnancy outcomes and complications, as well as patient-reported assessments of changes in both skin and joint disease activity at the onset of pregnancy, over the course of the pregnancy, and in the months following pregnancy. Simple statistics were used to compare outcomes before and after the diagnosis of PsA.

Results: The survey was completed by 40 women with PsA. The majority (93\%) were white, non-Hispanic with a high level of education $(40 \%$ completed college and another $30 \%$ either started or finished a graduate degree); $62.5 \%$ were married. The average age at the time of the study was 37.4 (SD 7.9) years and age at PsA diagnosis was 30.9 (8.4) years.

Twenty-five women reported they had ever tried to become pregnant, and of those, 9 had been unable to become pregnant after 12 months of trying or had been diagnosed with infertility by a physician (36\%). The reasons for infertility or inability to become pregnant included polycystic ovarian syndrome $(44 \%)$, problem with ovulation $(11 \%)$, problem with uterus $(11 \%)$, elevated prolactin $(11 \%)$, infection in pelvic area $(11 \%)$, and/or cervical problems $(30 \%)$. Infertility was unexplained in $33 \%$.

There were 70 pregnancies to 26 patients, with 37 pregnancies occurring after the diagnosis of PsA (see table). Pregnancy outcomes following PsA diagnosis were worse than those prior to PsA diagnosis, particularly the rate of pregnancy loss $(32 \%$ compared to $12 \% ; p=0.05)$ and preterm birth $(48 \%$ compared to $21 \% ; p=0.02$ ). Only $24 \%$ of patients took psoriasis or arthritis medications during pregnancy. The most commonly used medications during pregnancy were TNF inhibitors (16\%), corticosteroids ( $8 \%)$, and DMARDs $(5 \%)$.

The large majority of patients had minimal arthritis and psoriasis during pregnancy.

\begin{tabular}{|c|c|cc|}
\hline Table. Pregnancy outcomes before and after psoriatic arthritis diagnosis. \\
\hline & Overall & $\begin{array}{c}\text { Prior to PsA } \\
\text { Diagnosis }\end{array}$ & $\begin{array}{c}\text { After PsA } \\
\text { Diagnosis }\end{array}$ \\
\hline Number of Pregnancies & 70 & 33 & 37 \\
Live Births & $47(67 \%)$ & $24(73 \%)$ & $23(62 \%)$ \\
Spontaneous Abortion & $15(21 \%)$ & $4(12 \%)$ & $11(30 \%)$ \\
Stillbirth & $1(1 \%)$ & $0(0 \%)$ & $1(3 \%)$ \\
Ectopic Pregnancies & $1(1 \%)$ & $1(3 \%)$ & $0(0 \%)$ \\
Elective Termination & $6(9 \%)$ & $4(12 \%)$ & $2(5 \%)$ \\
Preterm Birth & $16 / 47(34 \%)$ & $5 / 24(21 \%)$ & $11 / 23(49 \%)$ \\
Preeclampsia & $11 / 46(24 \%)$ & $5 / 23(22 \%)$ & $8 / 23(35 \%)$ \\
Abnormal Infant & $1 / 47(2 \%)$ & $2 / 24(8 \%)$ & $2 / 25 *(8 \%)$ \\
Adverse Pregnancy Outcome & $33(47 \%)$ & $10(30 \%)$ & $23(62 \%)$ \\
\hline
\end{tabular}

*two twin pregnancies 